\title{
تطبيقات الوسائط المتعددة في الصحافة الاكترونية
}

\section{برنيس نعيمة \\ كلية علوم الإعـلام و الاتصلال و السمعي لعيدي البصري \\ جامعة صالح بوبنيدر - قسنطينة-

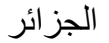

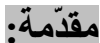

تمثل تقنيات الوسائط المتعددة

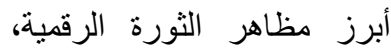
حيث أناحت تقنيات الحاسوب والانترنت تقديم المواد المقروءة

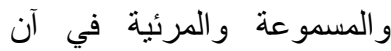

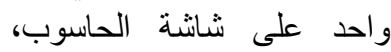

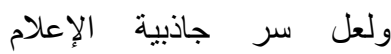
الالكتروني يعود إلى هذه التقنية

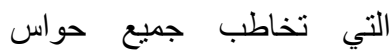
الإنسان ومداركه العقلية، حيث جيث

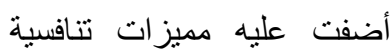
مما جعله أكثر فاعلية وجذبا مدئ للمنلقي،

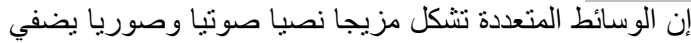

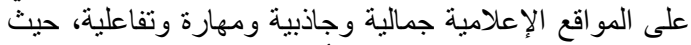
انصهرت بواسطتها الفروق والأبعاد بين الوسائل والئل الإعلامية،

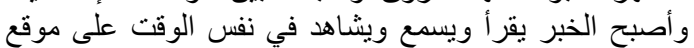

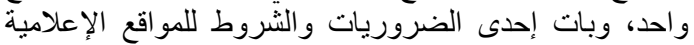

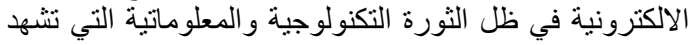

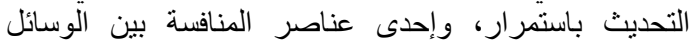

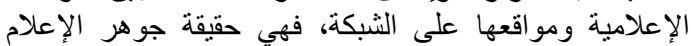

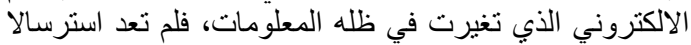

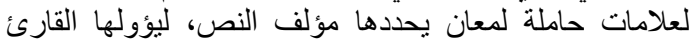

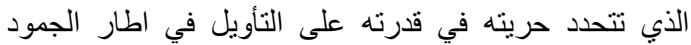

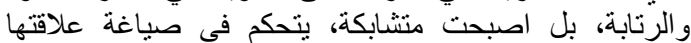

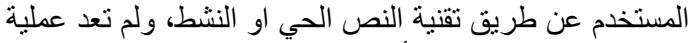

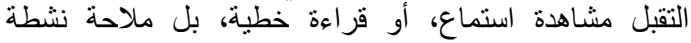

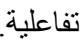

\section{Résumé:}

Le multimédia est une combinaison de textes, sons et photos qui donnent aux sites médiatiques une certaine attirance et interactivité. Grâce à ces outils les informations sont diffusées instantanément sur les différents sites web et la mise à jour régulière des infos est assurée.

En effet, le multimédia forme désormais le moteur de la presse électronique qui a changé de profil, car il ne s'agit plus d'un simple envoi de données et de signes pleins de sens déterminés par l'auteur, qui dépend de la capacité limitée souvent du récepteur. Par contre aujourd'hui les textes sont soumis à un control de formulation qui amplifie une relation avec l'utilisateur via les textes interactifs, et ceci a mené à une réceptivité plus dynamique loin d'écouter, lire ou écrire passivement, tout en créant une navigation interactive active 


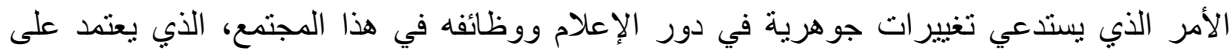

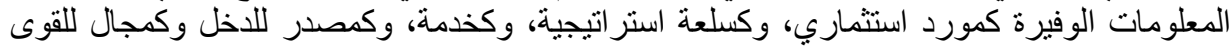

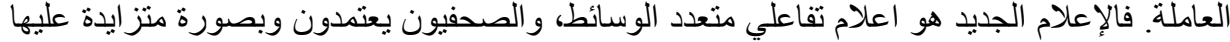

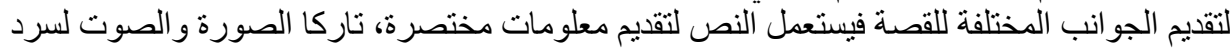

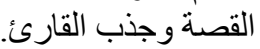

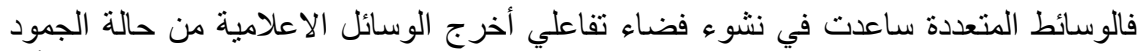

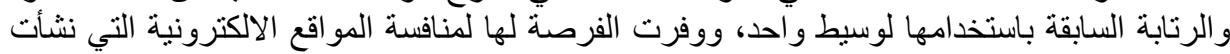

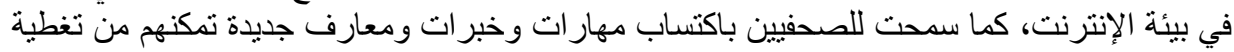

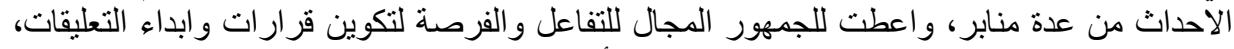

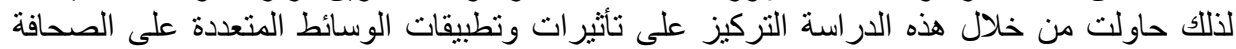

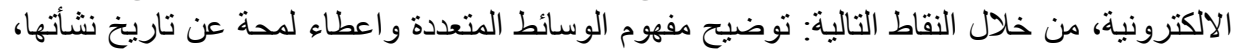

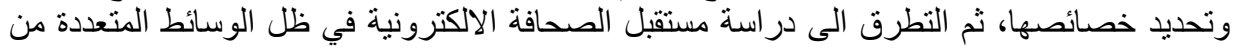

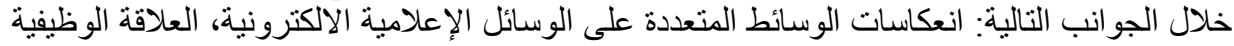

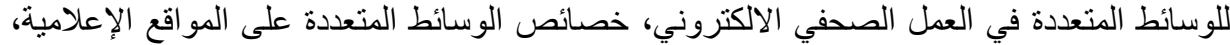

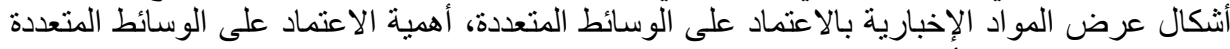

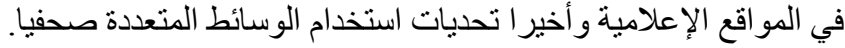

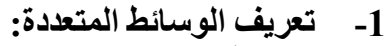

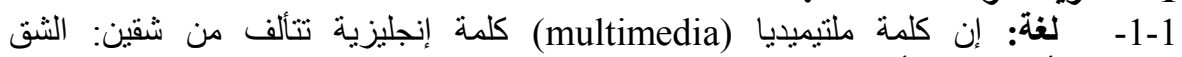

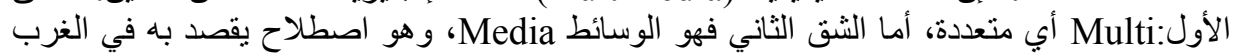

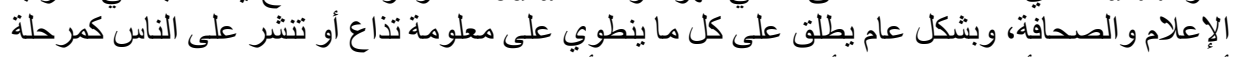

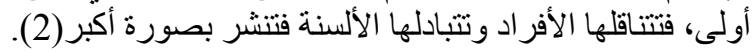

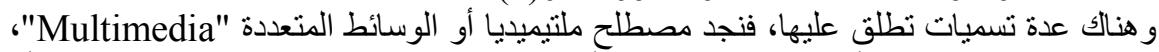

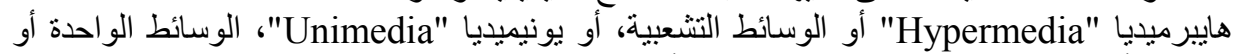

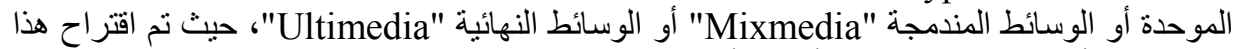

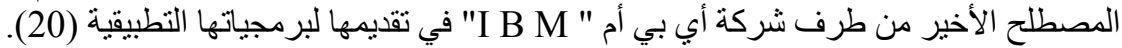

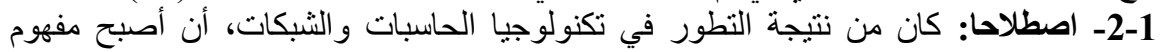

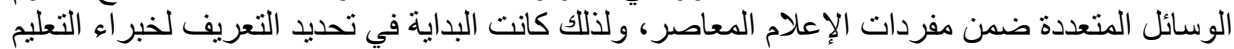

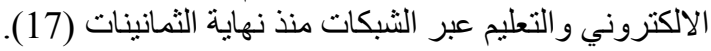

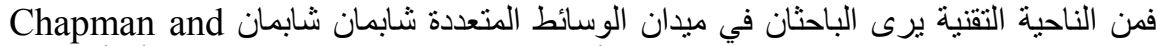
Chapman

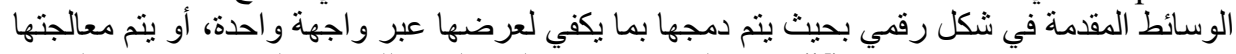

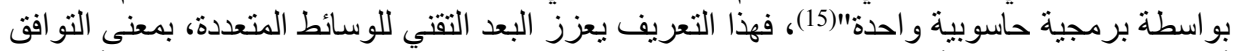

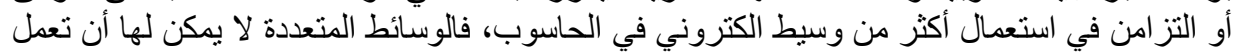

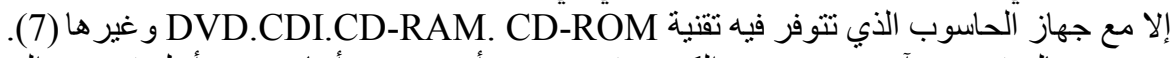

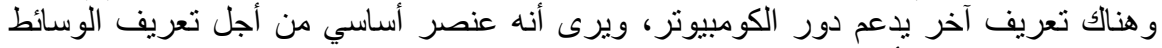

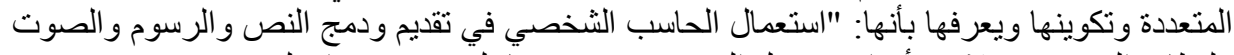

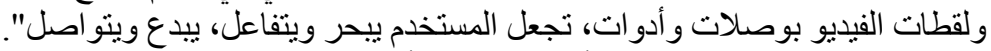

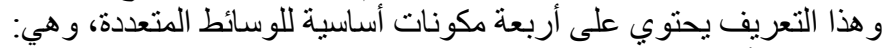

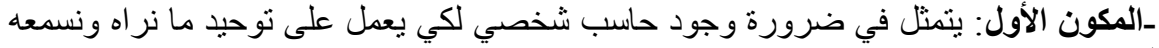

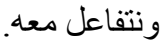
ـالمكون الثاني: لابد من وجود وصلات أو روابط "Link" التي توصل المعلومات، وتتمثل في النصوص الرسوم الصور، الصوت، ولقون ولقطات الفيديو. روان 
ـالمكون الثالث: يتمثل في أدوات الإبحار التي تجعل المستخدم يبحر على الثبكة ليصل للمعلومات

ـألمكون الرابع: يتمثل في ضرورة توافر طرق تمكنك من جمع ومعالجة وتوصيل معلوماتكا

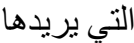

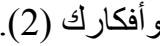

وفي حالة عدم تو افر المكونات الأربع مجتمعة ومكتملة فهذا يؤدي إلى عدم وجود و وسائط متعددة،

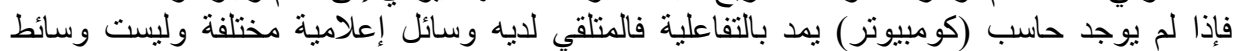

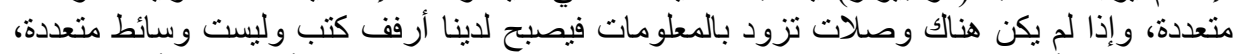

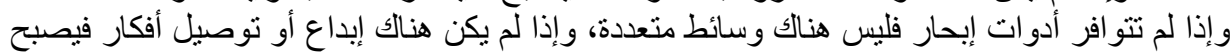

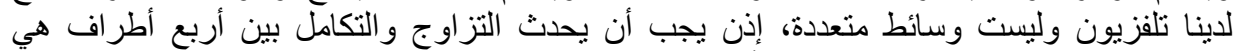

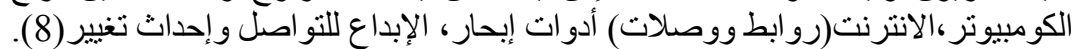

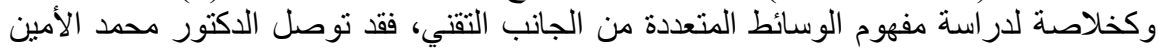

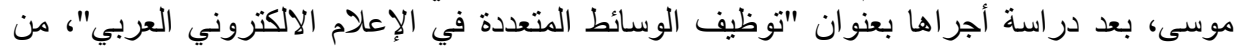

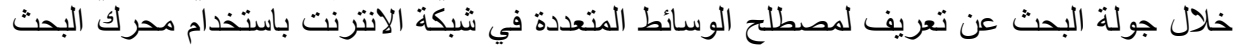

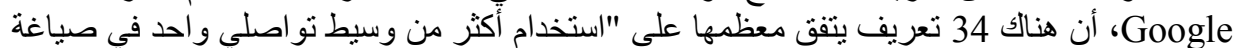

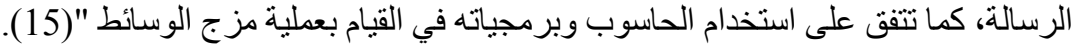

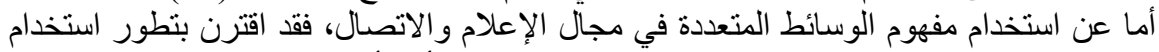

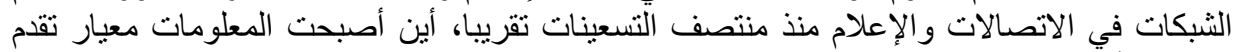

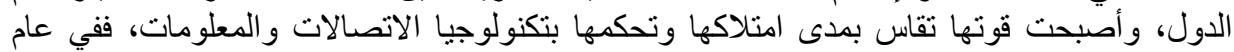

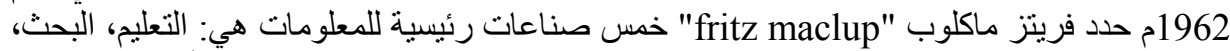

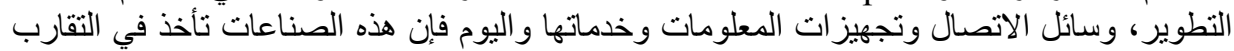

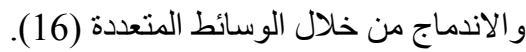

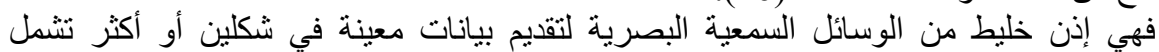

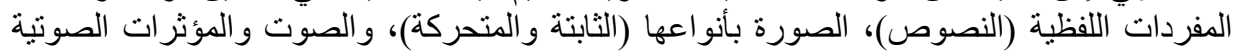

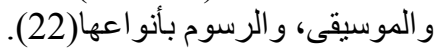

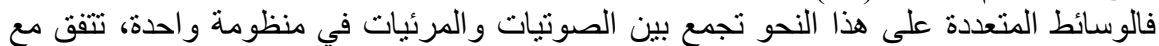

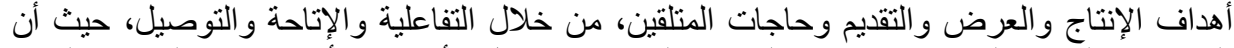

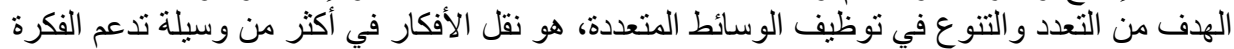

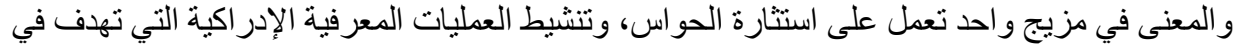

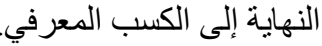

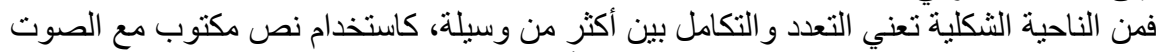

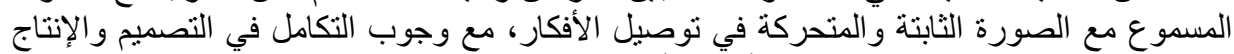

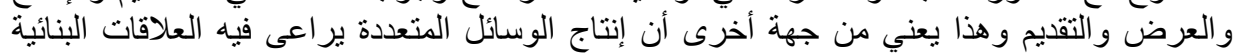

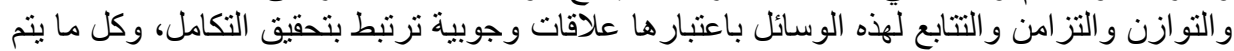

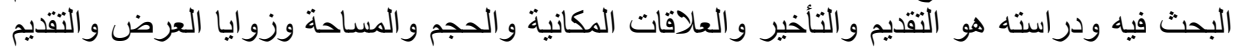

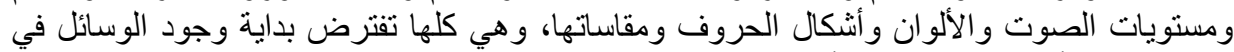

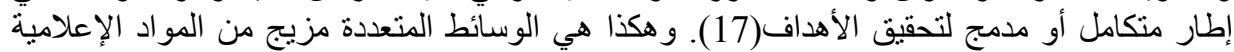

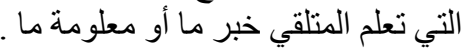

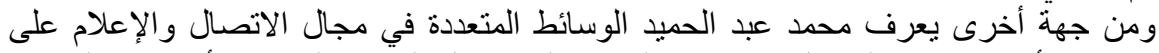

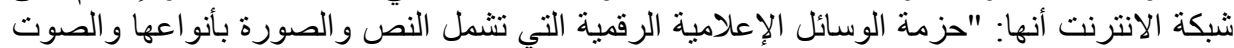

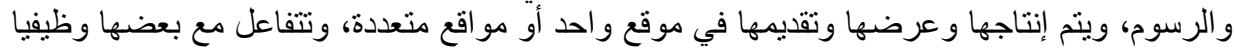
في إطار نظام مؤسسي يتيح للمتلقي الوصول والتجول ولتول والاختيار الحر، بجانب المشاركة في بناء

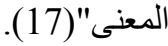


فالوسائط المتعددة قد أوجدت تغيير ات كبيرة في طر ائقنا في العمل، التواصل والاستهلاك و وقد

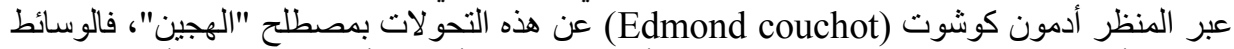

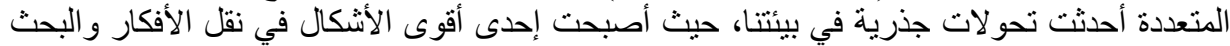

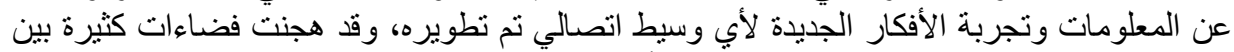

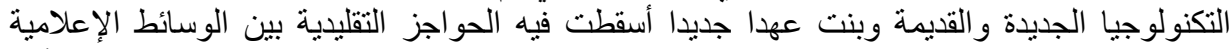

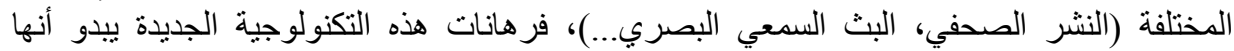

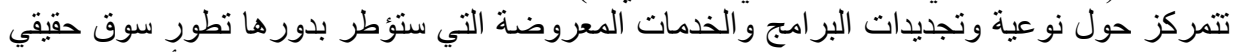

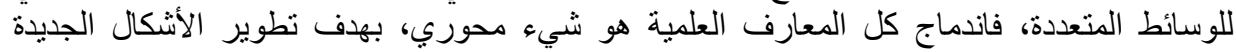

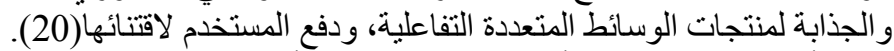

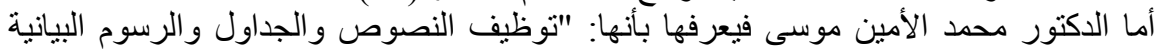

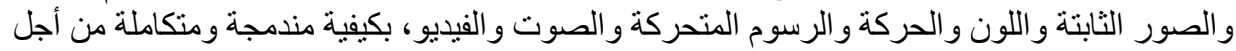

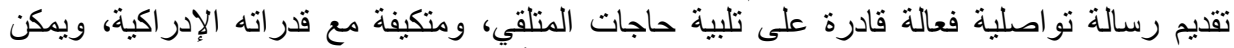

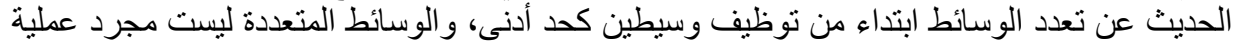

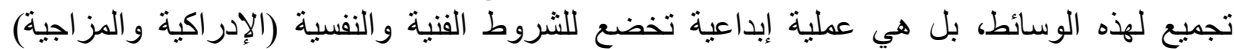
المو اكبة لعملية المتلقي" (15).

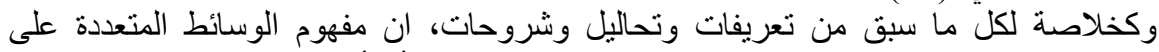

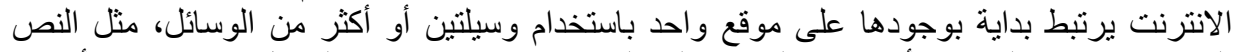

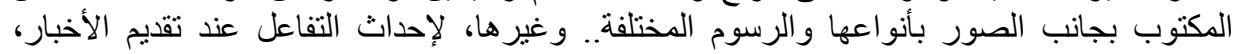

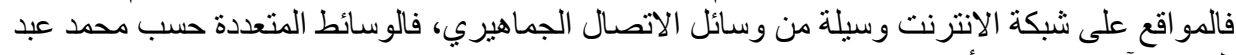
الحميد وآخرون تعني أنها (17):

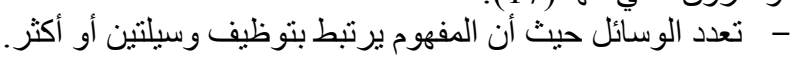
- - التنوع في نوظيف الوسائط فلا يكفي استخدام وسيلة أو وسيلتين لمر ات ات عديدة، حتى يقال أنها - - - التكامل في التوظيف و الأهداف و الدلالة.

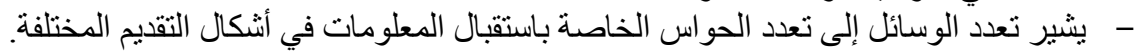

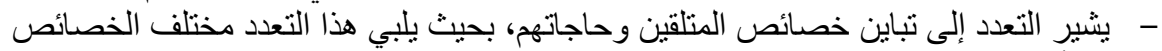

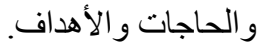

- قاعدة بيانات تضم ملفات هذه الوسائل سواء كانت في برنامج واحد أو برامج متعددة، مع إمكانية الربط بينها في التوظيف وانضئ والاستخدام.

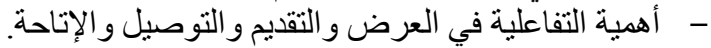

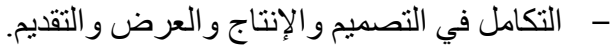
- - - إضفاء المزيد من الجمالية والخدمات و التفاعلية على المو اقع الإعلامية.

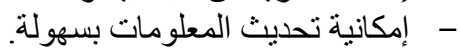
- - - - إمكانية اللجوء السريع للأرشيف الالكتروني.

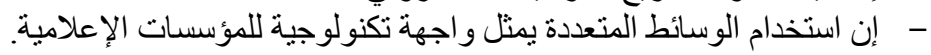

2-محة تاريخية عن الوسائط المتعددة:

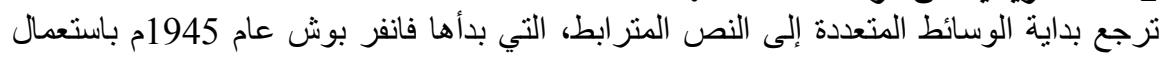

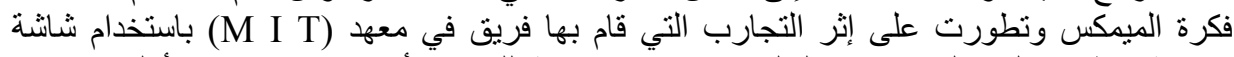

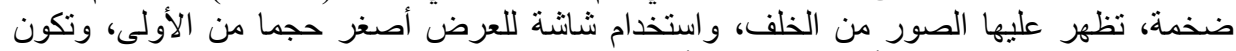

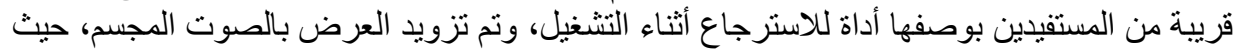

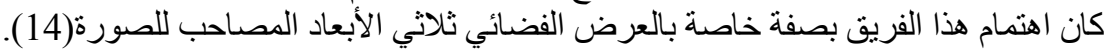


إضافة إلى مجمو عة أفكار نيكو لاس نيغروبونتي التي كون بها مجمو عة الآلة الهندسية في معهد التها

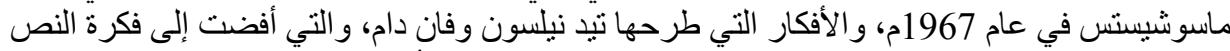

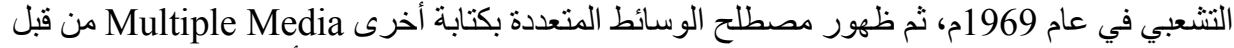

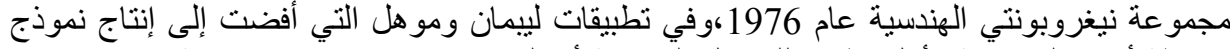

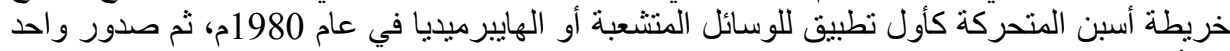

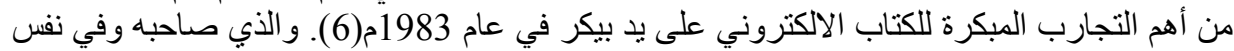

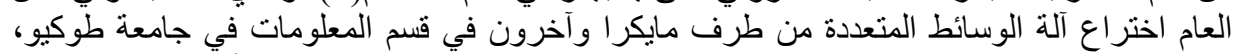

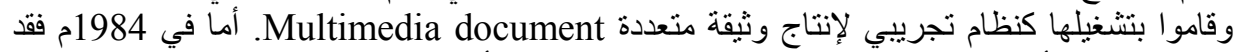

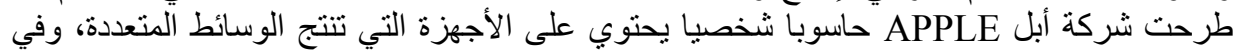

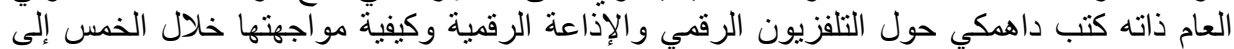

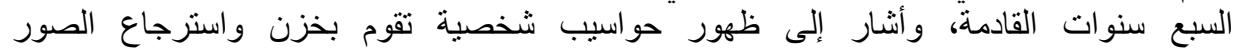

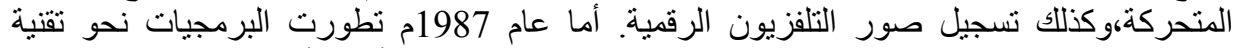
الوسائط المتعددة على مستوى البيت باستخدام (Hyper card) لشركة أبل. و أصبح هذا لمان التطور يحسب

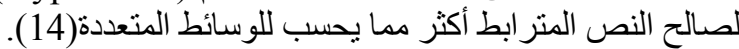

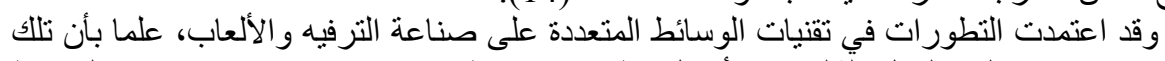

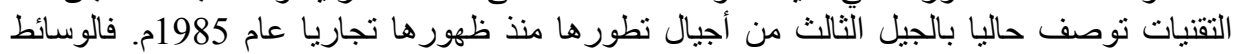

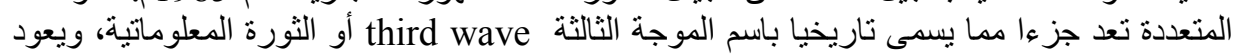

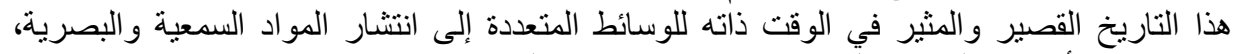

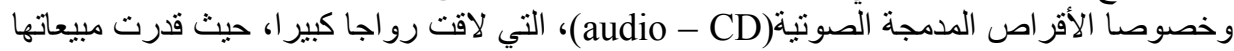

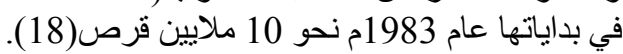

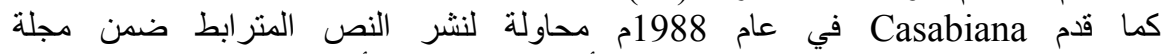

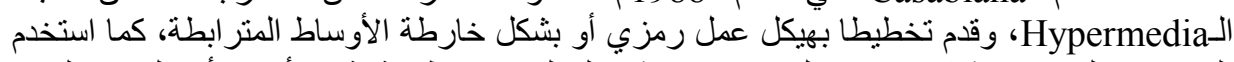

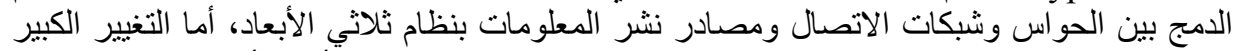

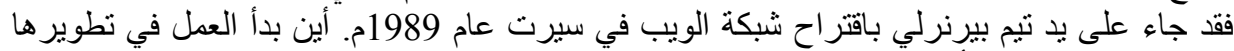

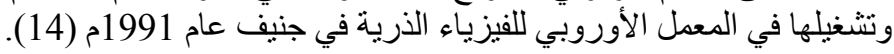

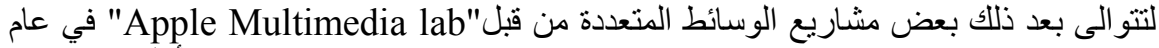

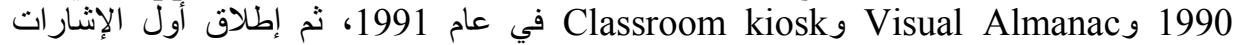
الصوتية عبر شبكة الانترنت في عام 1991، وظهور مستعرض موزاييك في 1993 ونيتكسب في

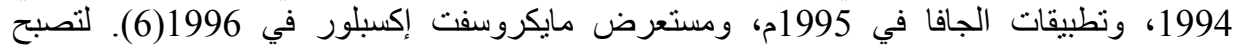
الانترنت وسيطا متعدد الإعلاميات.

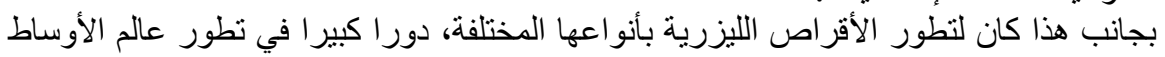

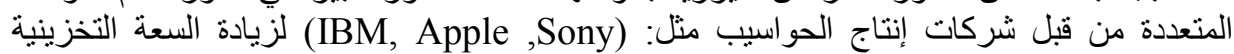

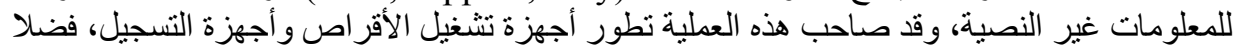

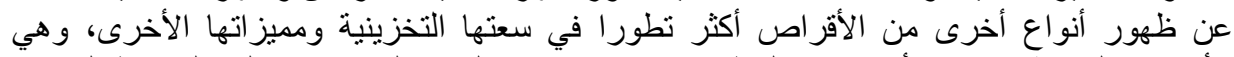

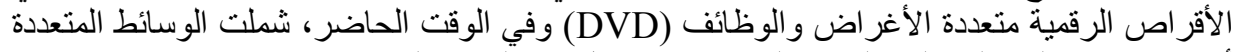

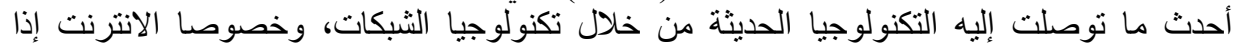

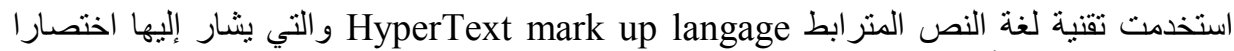

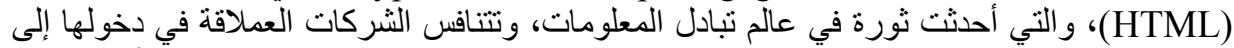

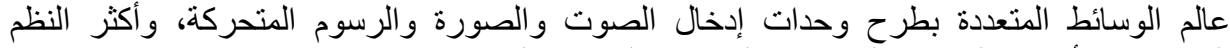

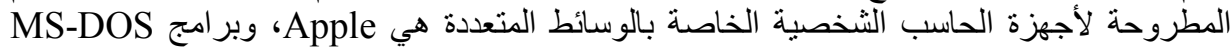

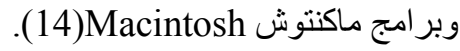




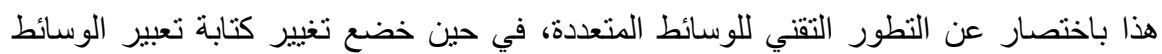

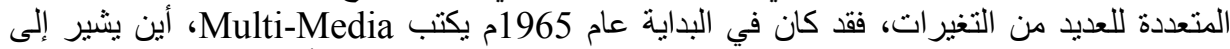

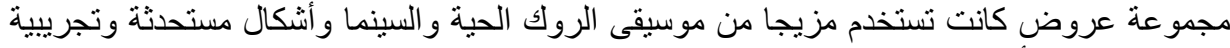

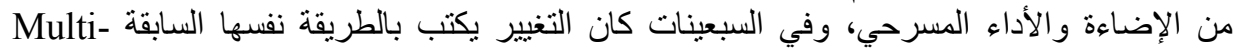
Media

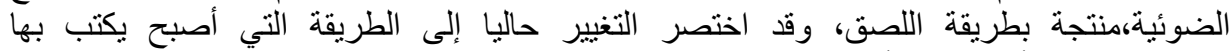
Multimedia

يكتبون تعبير الإعلاميات المتعددة(6). 3- خصائص تكنولوجيا الوسائط المتعددة:

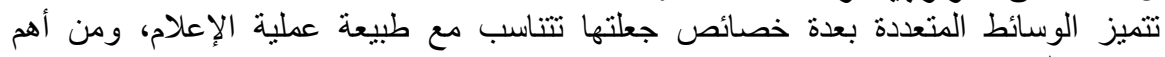

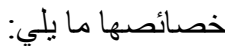

1- التفاعلية interactivity: وتعني إمكانية الزائر في أن يتفاعل ويتو اصل بشكل مبانشر،

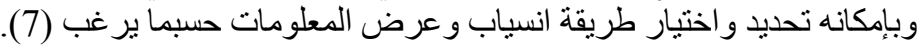

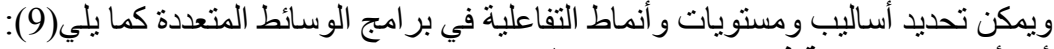
أ-ـ أساليب التفاعلية في عروض الوسائط المتعددة: - - متابعة العرض بأكمله من البداية إلى النهاية.

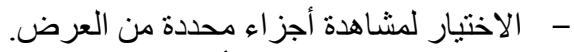
- - اختبار جزئية فرعية من أحد البدائل في قائمة الخيار ات ومشاهداتها.

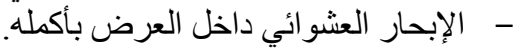

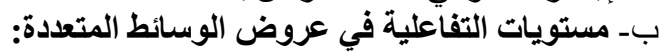
- - مستوى المشاهدة و التلقي مع إمكانية التحكم في تتابع العرض وضئن والاختيار من البدائل المتاحة في

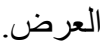
- - مستوى العرض و المشاهدة و التلقي للمعلومات فقط.

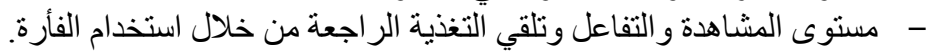

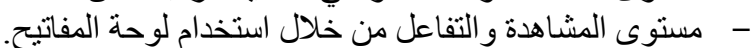

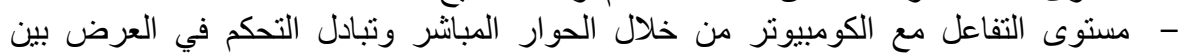

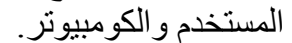

ج- أنماط التفاعلية في عروض الكئن الوسائط المتعددة:

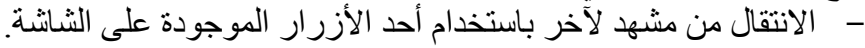

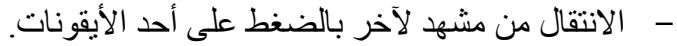

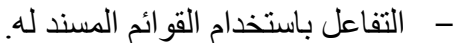

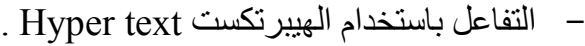

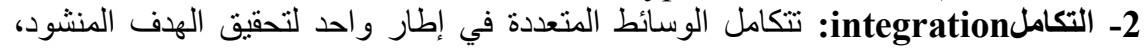

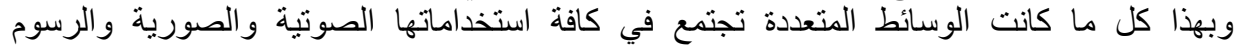

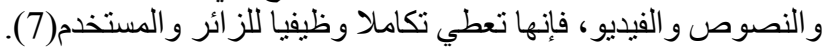

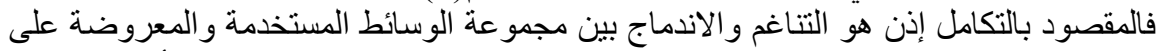

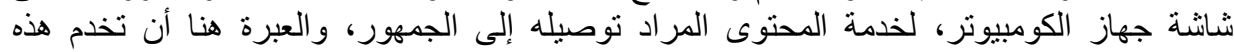

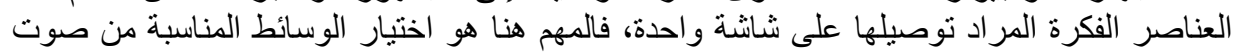

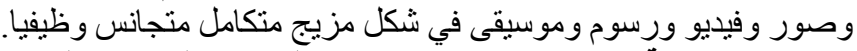

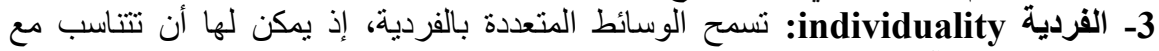

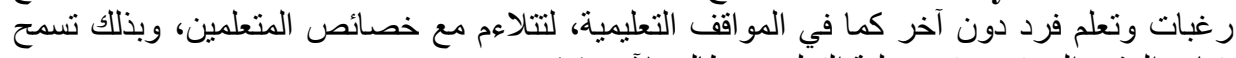
بتباين الوقت المستخدم في عملية التعلم من طالب لآخر (7). 
فصفة الفردية تقتضي النظر إلى الفروق الفردية بين الجمهور واختلاف قدر اتهم واستعداداتهم،

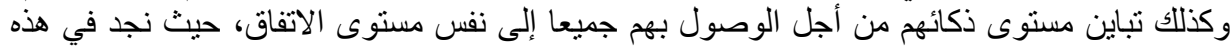

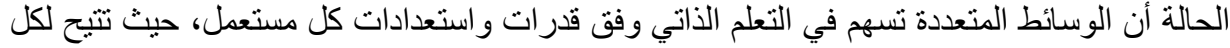

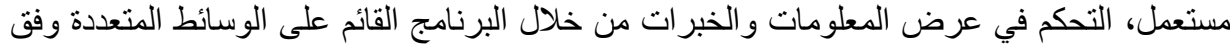
قدر اته و إمكاناته وسر عته الذاتية.

4- التتوع diversity: تنتوع الوسائط المتعددة نتيجة إمكانياتها في استخدام وتنويع العناصر

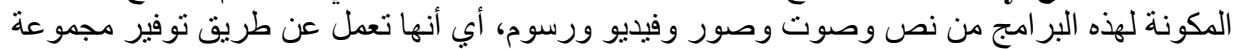

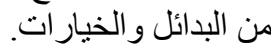

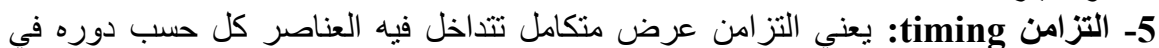

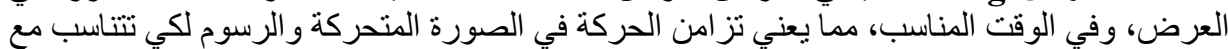

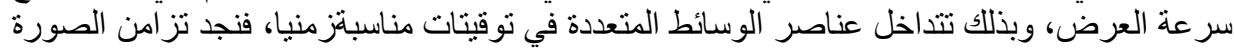

مع الصوت و غيره، مما يحقق التفاعل و التكامل (3).

6- الرقمنة والكونية Digitalization and Globality: الرقمنة في تكنولوجيا الوسائط

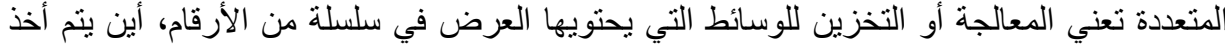

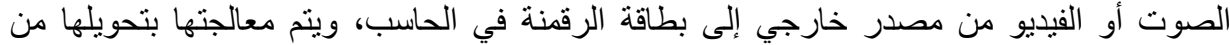

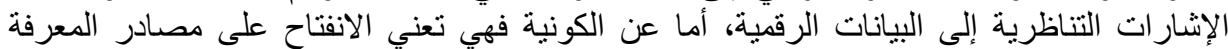

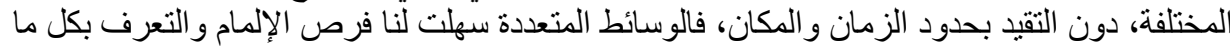

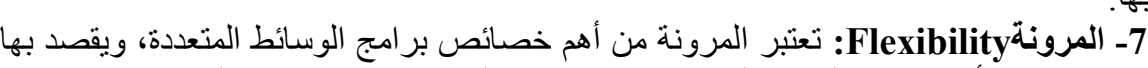
بحيط بها.

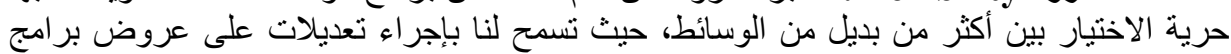

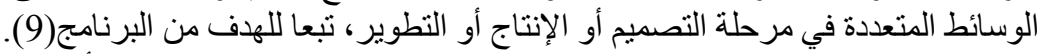

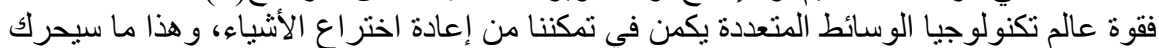

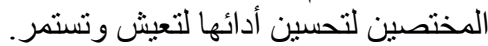

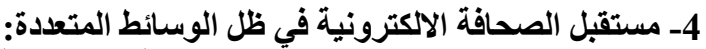

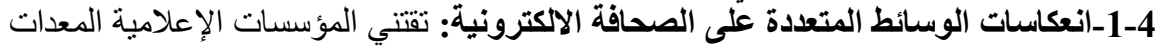
التقنية الحديثة لتحقيق هدفين: الهذف الأول: يتعلق باستخدامها الاستخدام الأمثل في إنتاج المو اد الإعلامية.

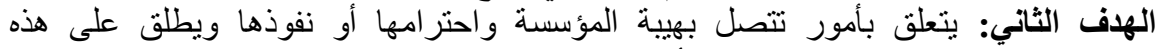

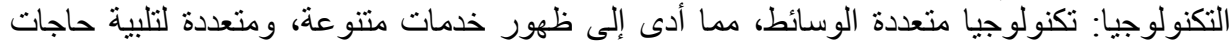

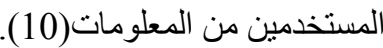

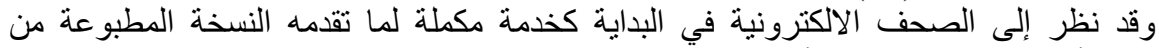

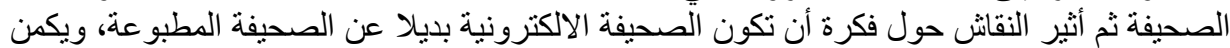

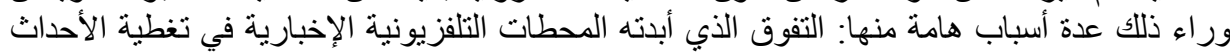

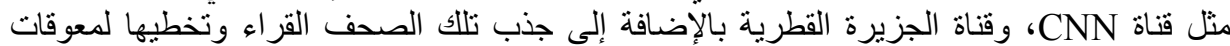

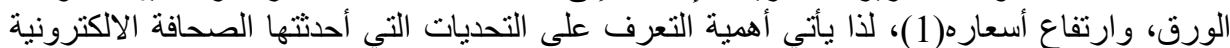

الرقمية من خلال ذكر المميزات غير المتوفرة في الصحف المطبوعة نذكر منها الميا على سبيل المثال(1):

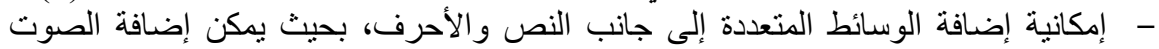

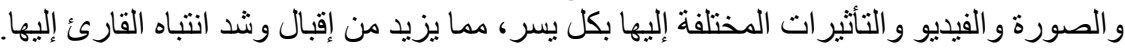

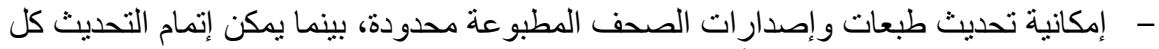

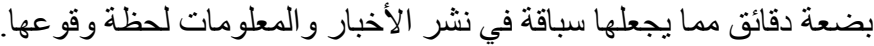

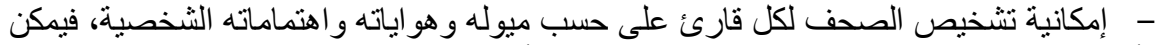

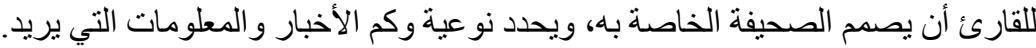


- - إمكانية التفاعل مع القارئ، فالقارئ هنا بستطيع التحاور و المناقشة و إبداء الآراء مع الكتاب و النقاد و القر اء الآخرين حول نقاط مختلفة.

- - إمكانية الاطلاع على الأرشيف الالكتروني للأعداد السابقة من الصحيفة بكل بسر وسهولة عبر قاعدة البيانات الخاصة بالجرئة عالإيدة.

ويشير غوردن إلى أن الانترنت بمكن أن تقدم على الأقل ثناث قدرات تساعد في جعل الصحافة

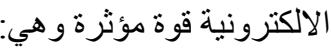
1- انفتاح الانترنت وقدرته على الوصول للجمهور.

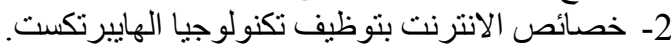

3- برنامج RSS التي تساهم في وصول الموليف الموضوعات ذات ذات الصلة التي يحتاجها

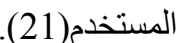

ويؤيد توم فيليبس الاتجاه القائل بأن قوة الصحافة الرقمية تكمن في القدرة على دمج وسائل الإعلام

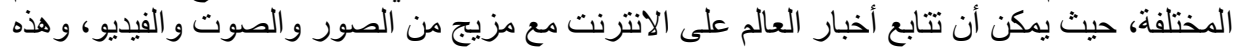

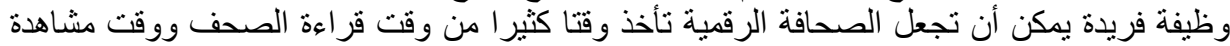

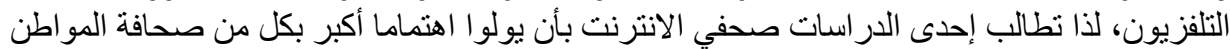

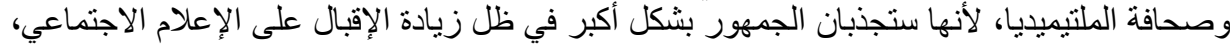

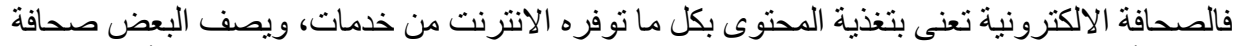

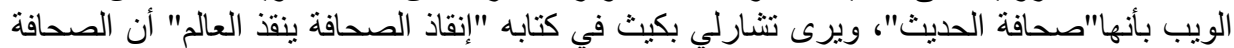

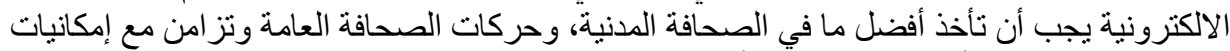

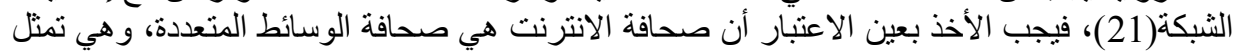

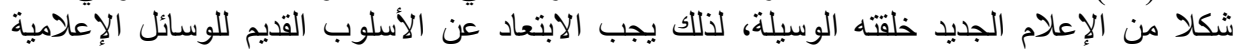

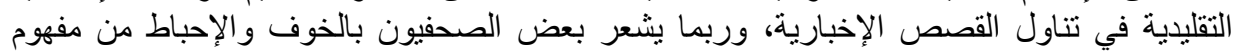

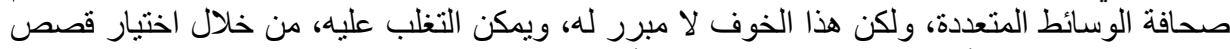

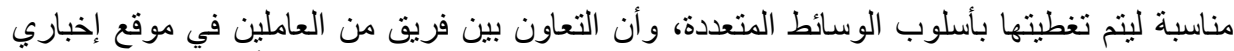

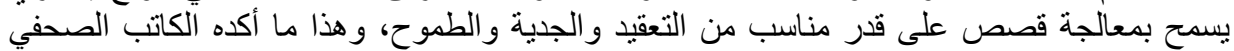

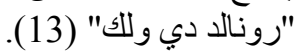

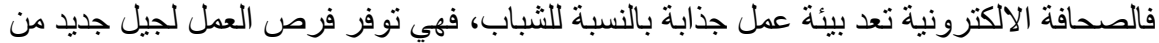

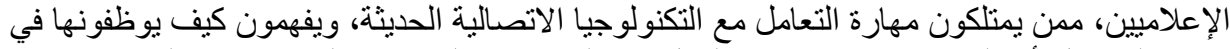

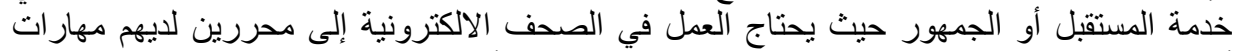

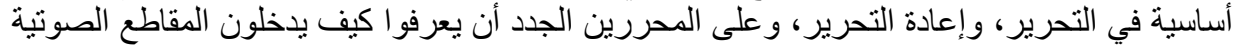

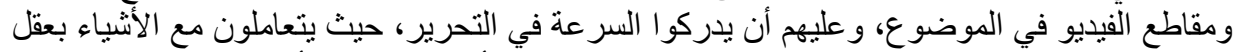

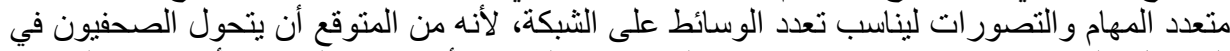

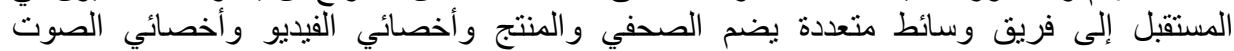

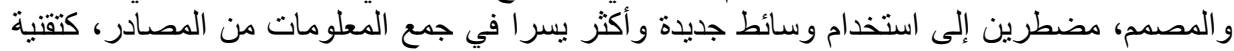

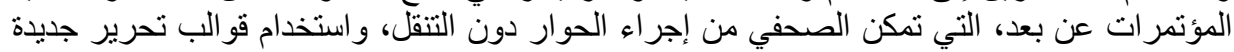

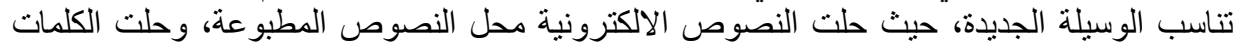

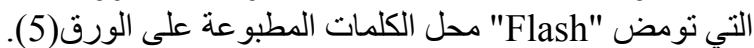

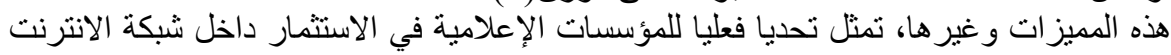

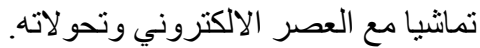

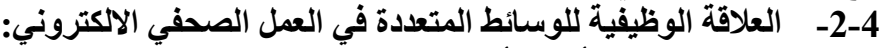

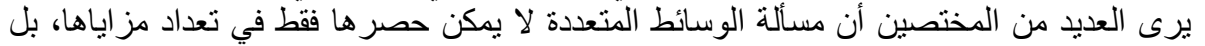

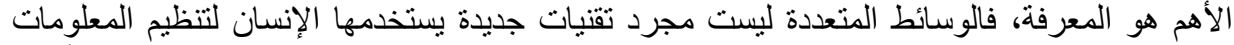
وتوثيقها وتوزيعها، بل هي مؤسسة لثقافة جديدة في عو الم مختلفة، تتخير فيها علاقتته بالآخرين وبالأشياء التاء 
من منطلقات منها: أن التكنولوجيا هي من المحددات الرئيسية للثقافة، فالكومبيوتر و الوسائط المتعددة

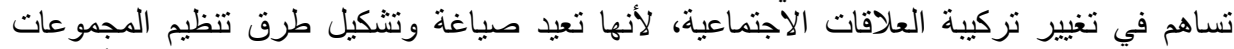

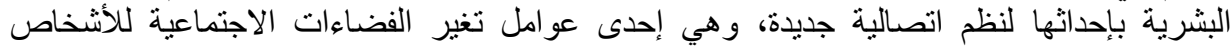

وخاصة بالنسبة للأجيال الجديدة(4).

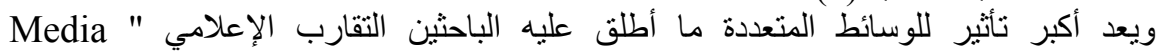
convergence

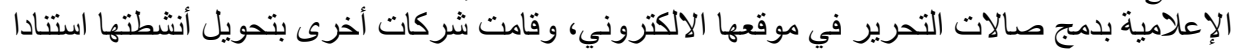

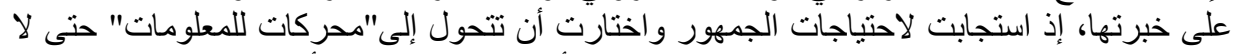

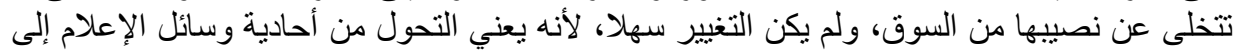

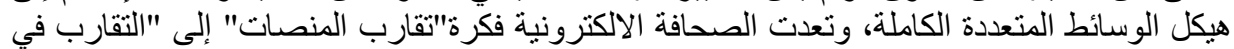

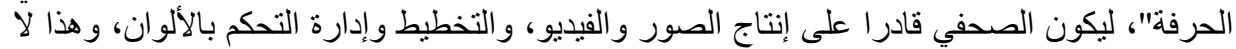
يقل أهمية عن الكتابة الجيدة، وصار التصميم (تصميم المواقع) في صلب صناعة الصحافي الصافة الجديدة

فلقد تحدت الصحافة نفسها وفريقها لكي تخطو بهم خطوة خارج خبراتها، ومحاولة تنسيق

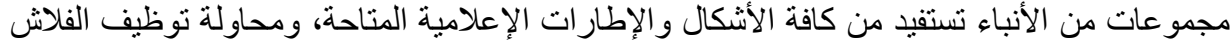

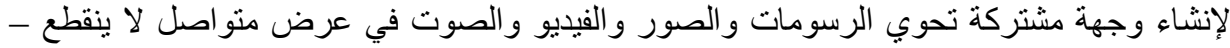

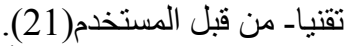

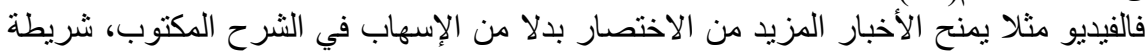

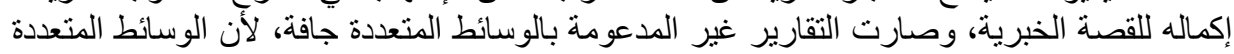

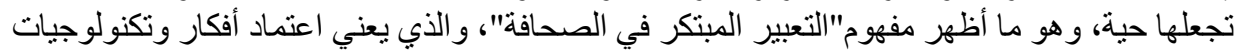

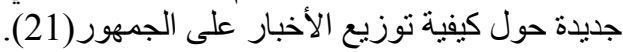

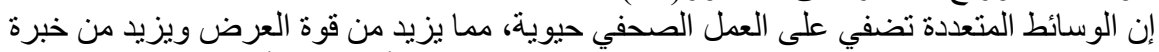

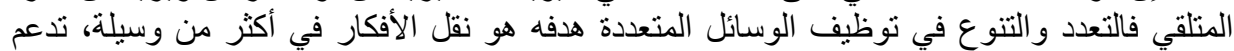

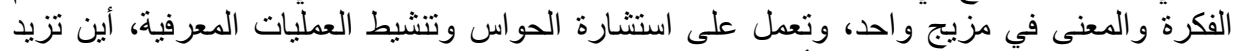

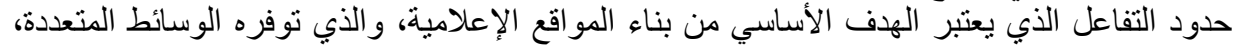

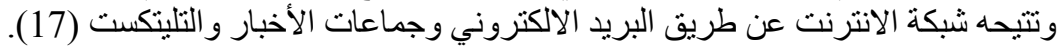

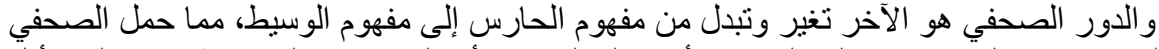

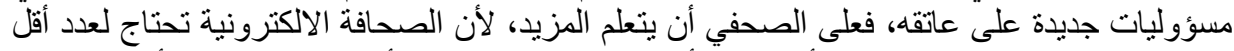

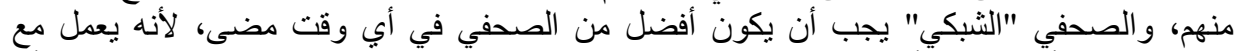

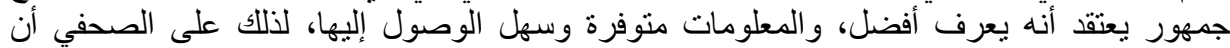

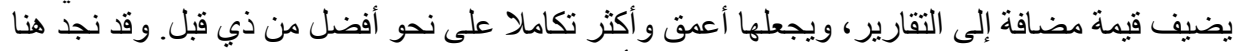

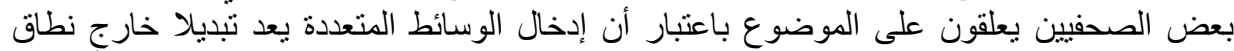

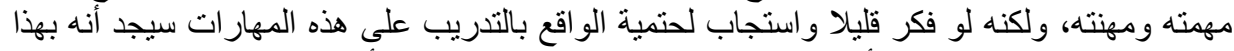
يخدم رسالته، ويصل بها إلى أكبر عدد من الجمهور، ويجعلها تحظى بأكبر قدر من التفاعلية و التقدير

والاهتمام منهم(21).

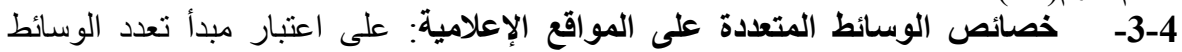

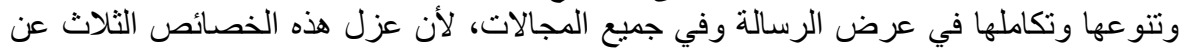

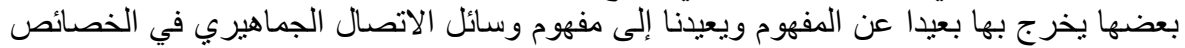
و الوظائف المنفردة لكل وسيلة، وعلاقتها بالجمهور الخاص بهانيا، ويمكن تحديد هذه السيمات الهيات في(17): (17)

- - مئن إنخدامها في المو اقع الإعلامية مر هون بخصائص تكنولوجيا الثبكات وحاجات التنلقين، وبذللك فإنه ليس شرطا استعمالها مجتمعة، كما أنها ليست ضرورة للعرض و التقديم، ولكنها 
ميزة تميز موقعا إعلاميا عن آخر بيتهدف الوصول إلى المتلقين، وفقا لحاجاتهم وتفضيلاتهم

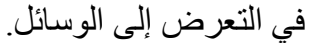

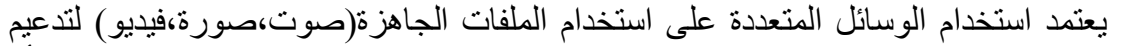

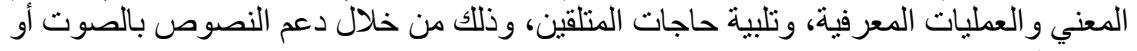
صور الفيديو.

- يعتبر الاستخدام الحي"البث" للوسائط مثل اللقاءات الصوتية أو صور الفيديو في مواقع

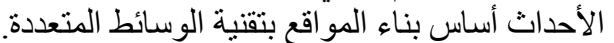

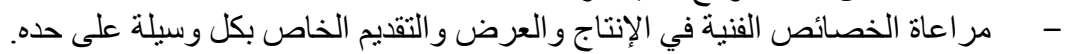

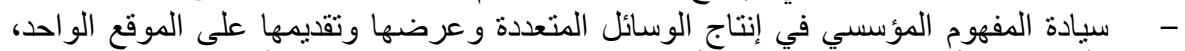

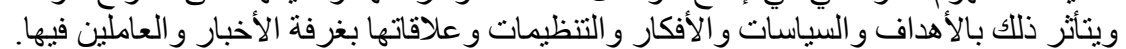

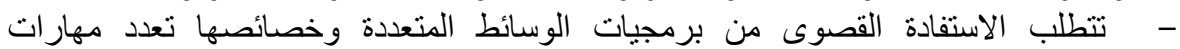

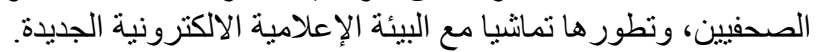
4-4-4 أثكال عرض المواد الإخبارية بالاعتماد على الوسائط المتعدادة:

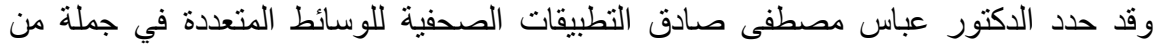

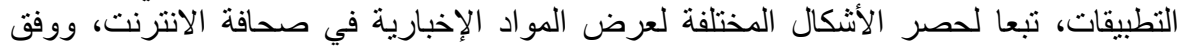
التجارب التي عرضت في مو اقع المؤسسات الصحفية الكبيرة في: -

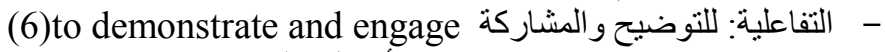

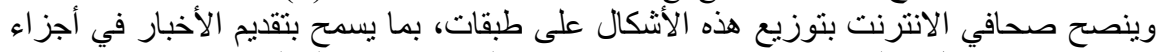

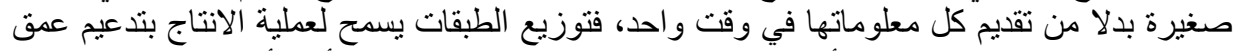

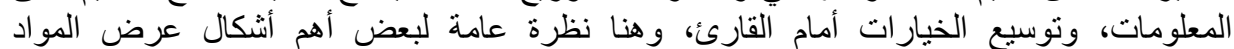
- النص الطباعي: يمثل الثكل الأساسي لعرض الأخبار في صحافة الانترنت.

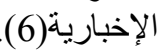

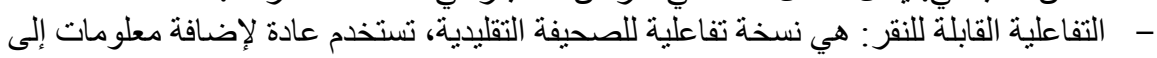

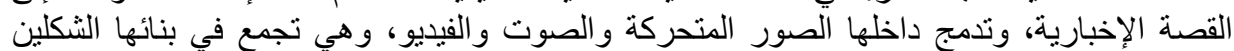
الخطي و اللاخطي في بناء القصة. داخلة

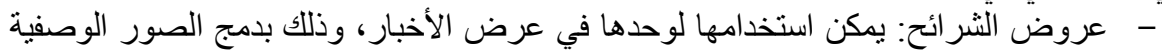

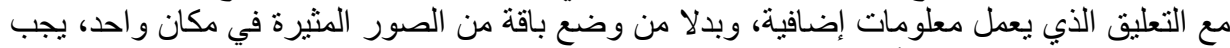

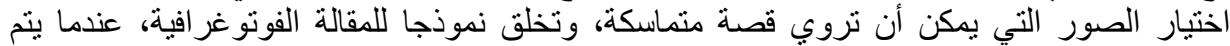

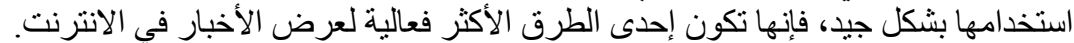

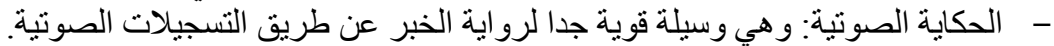

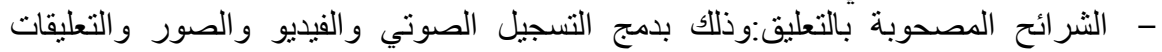
الصوتية القصيرة لبناء قصص إخبارية قوية.

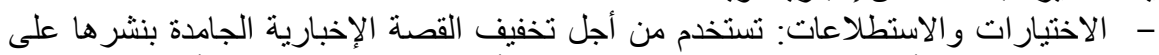

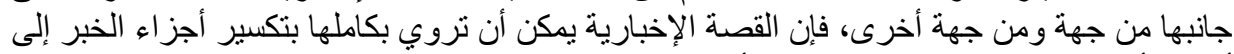

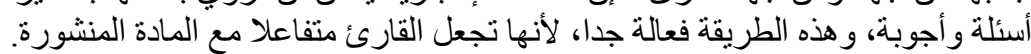

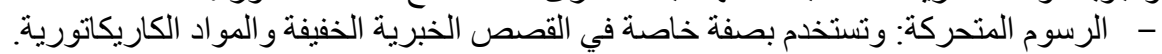

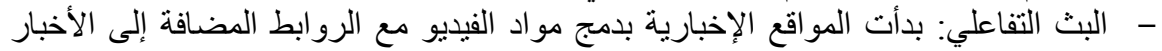

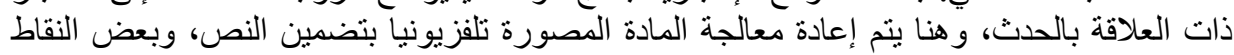
الحية والوصلات في الفيديو التي تمكن المشاهد من التنقل داخليا. 
- - الوسائط المتعددة التفاعلية: أين يكون كل عنصر من عناصر الوسائط المتعددة المكون للقصة الخبرية مجالا تفاعليا قابلا للنقر.

كل هذه الخصائص جعلت الوسائط المتعددة محط منافسة من قبل المؤسسات الإعلامية، في إطار

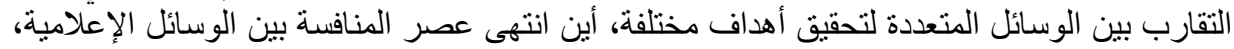

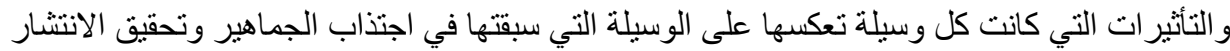

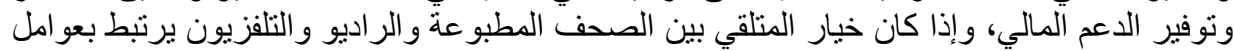

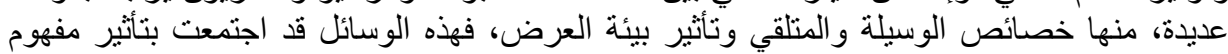

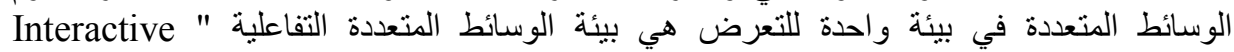
Multimedia Environment

$$
\begin{aligned}
& \text { 5-4- أهمية الاعتماد على الوسائط المتعددة في المواقع الإعلامية: } \\
& \text { نظم الثبكات بصفة خاصة(17) الاعيمة } \\
& \text { 1- تستغل الوسائط المتعددة لتحقيق هدف من الأهداف أو كلها: } \\
& \text { 1- تتمثل هذه الأهمية فيما يلي: الاعني: } \\
& \text { - - مضاء وقت أطول مع المادة الصحفية. }
\end{aligned}
$$

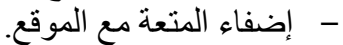

$$
\begin{aligned}
& \text { - - مساعدة المستخدم على تذكر معلومات أكثر. } \\
& \text { - - تذكر الاسم و العلامة التجارية للموقع. } \\
& \text { - - إعطاء المستخدم إحساسا بالترفياه(19). }
\end{aligned}
$$

2- هنالك جانب اقتصادي قوي في توظيف الوسائط المتعددة، فظهرت في أوروبا خدمة "الفيديو

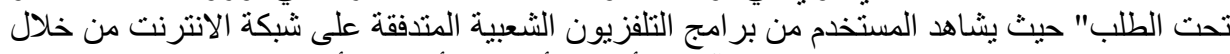

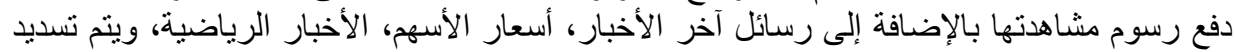

الفو اتير برسالة قصيرة من الهاتف المانف المحمول (21).

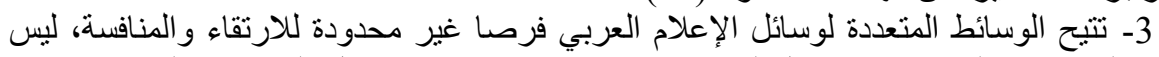

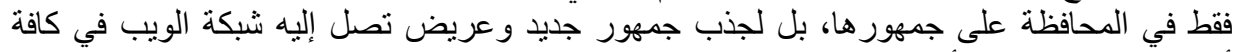

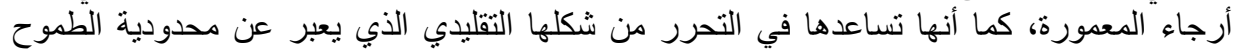

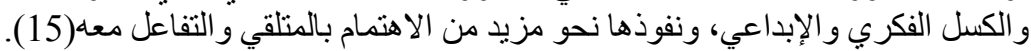

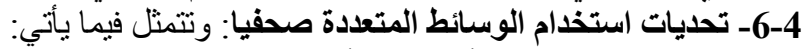

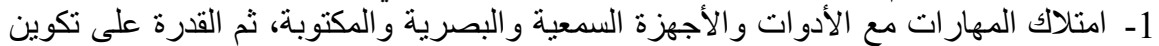

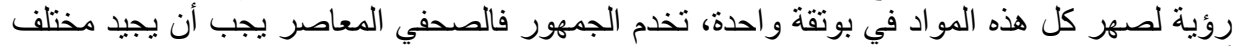

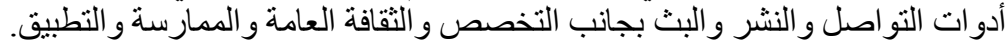

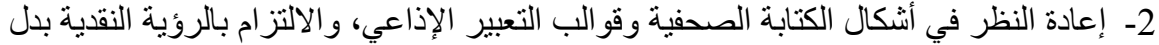

الرؤية السردية التاريخية للكتابة الصحفية (12).

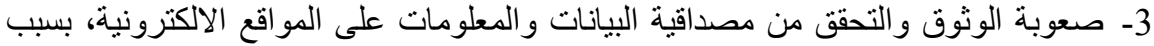

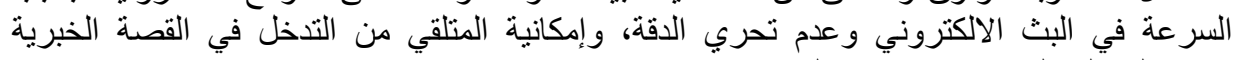

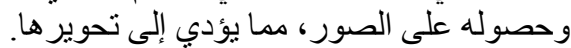

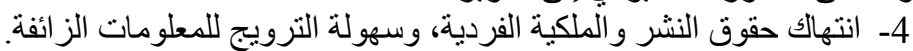

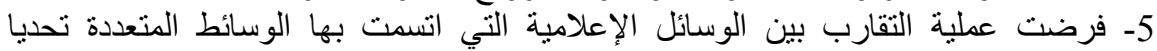

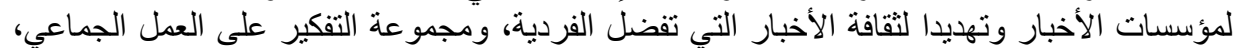

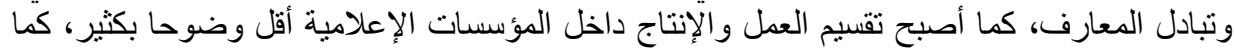

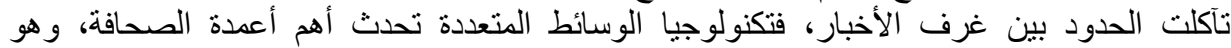
الصحفي المهني الذي يحدد للجمهور ما يرى ويسمع عن العالم (21). 


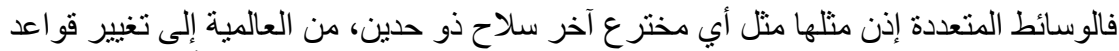

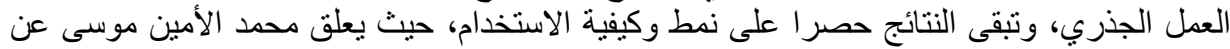

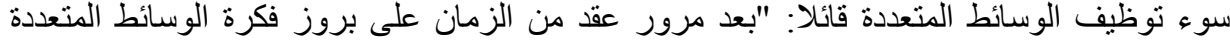

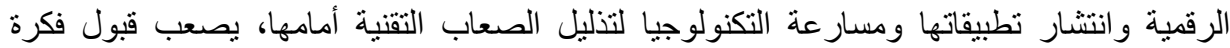

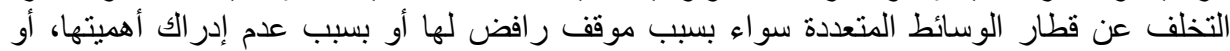
بسبب ضعف معرفي وتدريبي في التعامل معها و إنتاجها". فهي إذن تكنولوجيا حتمية في عصر الحتمية الترائ

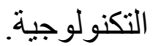

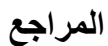

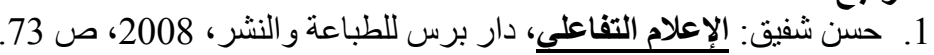
2. سن شفيق: الوسائط المتعدة وتطبيقاتها في المجال الإعلامي، رحمة برس للطباعة و النشر،

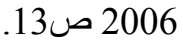

3. حسين حسن موسى:استخدام الوسائط المتعددة في البحث العلمى، دار الكتاب الحديث، القاهرة،

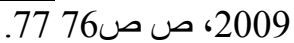

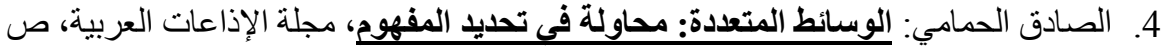

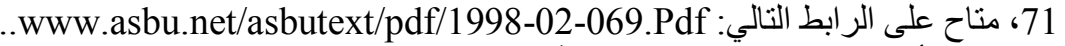
5. طارق سيد أحمد الخليفي: الإعلام المحلى في عصر المعلومات، دار النهضة العربية، بيروت، 2010

6. عباس مصطفى صادق: الإعلام الجديد_المفاهيم والوسائل والتطبيقات-، دار الثروق للنشر و التوزيع، ط1 2008 . 200 7. عباس ناجي حسن: الوسائط المتعدة في الإعلام الاككترونى، ط1، دار الصفاء للنشر و التوزيع، عمان 2016.

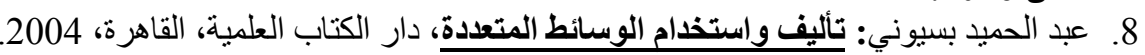

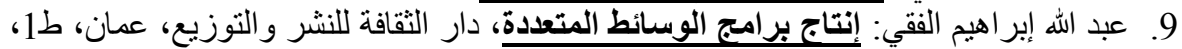
2011

10.علي عبد الفتاح علي: مستقبل الإعلام: تطوير الإعلام وفق تكنولوجيا الاتصال الحديث، دار

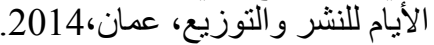

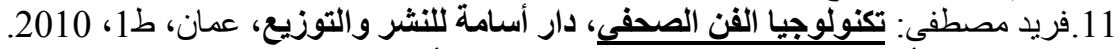

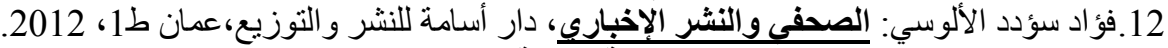

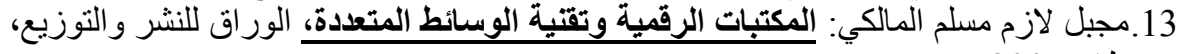

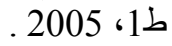

14.محمد الأمين موسى: توظيف الوسائط المتعددة في الإعلام الالكترونى العربي، مؤتمر صحافة

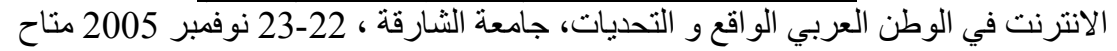

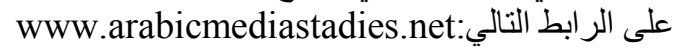
15.محمد جاسم فلحي: اتجاهات إعلامية معاصرة، متاح على الرابط التالي: -Www.ao . academy.org

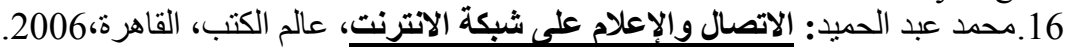

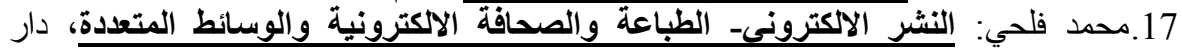

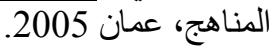

18.منار فتحي محمد: تصميم مواقع الصحف الاكترونية، دار العالم العربي، القاهرة، ط1، دس، دس.

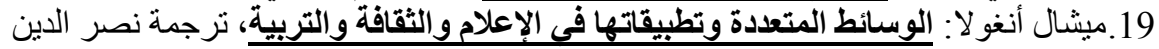

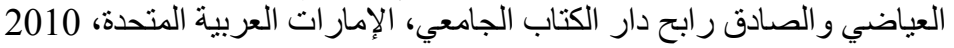


20.وسام كمال: الإعلام الاكترونى والمحمول بين المهنية وتحديات التطور التكنولوجي، دار

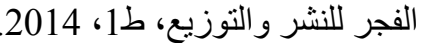

21.Steve Heath: Multimedia and communication on technology, the British library, London 1996. 